\title{
A Rare Case of Episiotomy Scar Endometriosis
}

\author{
Shanti Jeyaseelan ${ }^{1} \cdot$ Neha Kwatra $^{1}$
}

Received: 15 June 2015/Accepted: 1 October 2015/Published online: 17 December 2015

(C) Federation of Obstetric \& Gynecological Societies of India 2015

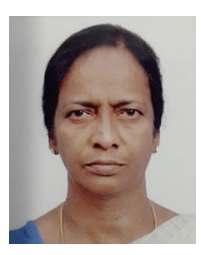

\begin{abstract}
About the Author
Dr. Shanti Jeyaseelan She is the Head of Department, Obstetrics and Gynecology, in Holy Family Hospital, Delhi, since 2002. She has done her undergraduate and postgraduate from AIIMS, New Delhi. She worked for 15 years in St. Stephens Hospital followed by 9 years in LKP Salve Institute before joining Holy Family Hospital as HOD. She is a life member of FOGSI and ICMCH. She has keen interest in high-risk obstetrics and gynaecological surgeries.
\end{abstract}

\section{Case Report}

Thirty-eight-year-old lady, mother of two children, came to OPD with history of cyclic pain in the perineal region which was gradually increasing in intensity and duration for 1 year. Pain was intense in last 4 months. Pain was related to her menstrual cycles. She also gave history of itching over perineal region.

Dr. Shanti Jeyaseelan, MD Obstetrics and Gynecology, Head of Department, Holy Family Hospital; Dr. Neha Kwatra, DNB Resident, Holy Family Hospital, Room No. 101, Aradhana Bhawan, Okhla Road, Delhi, 110025, India.

Neha Kwatra

nehakwatra6188@gmail.com

1 Holy Family Hospital, Room No. 101, Aradhana Bhawan, Okhla Road, Delhi 110025, India
She delivered her first child 10 years back with right mediolateral episiotomy followed by one more full-term normal delivery with episiotomy 7 years back.

Her menstrual history was normal, and her last menstrual period was 10 days back.

On examination, her vitals were within normal range and systemic examination did not reveal any abnormality.

Locally on inspection, previously healed episiotomy scar was seen. Perineal skin looked healthy. On palpation, a tender induration was felt along the entire episiotomy scar.

Clinically, episiotomy scar endometriosis was diagnosed, and she was prepared for surgical excision of endometriotic nodule.

Excision was done under anaesthesia. Excised tissue consisted of cystic spaces filled with chocolate-coloured fluid. Wound was repaired with proper haemostasis. Skin was closed with silk no.1.

Histopathology confirmed scar endometriosis (Figs. 1 and 2).

Patient was injected with Leupride $11.25 \mathrm{mg}$ post-operatively. She resumed her cycles after 4 months post- 


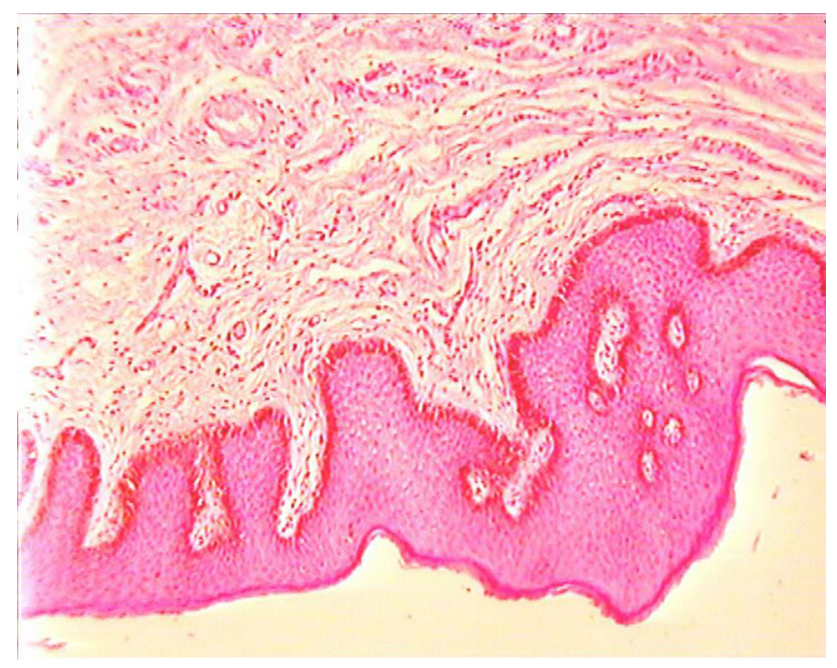

Fig. 1 Endometriotic glands and stroma in the subcutaneous tissue

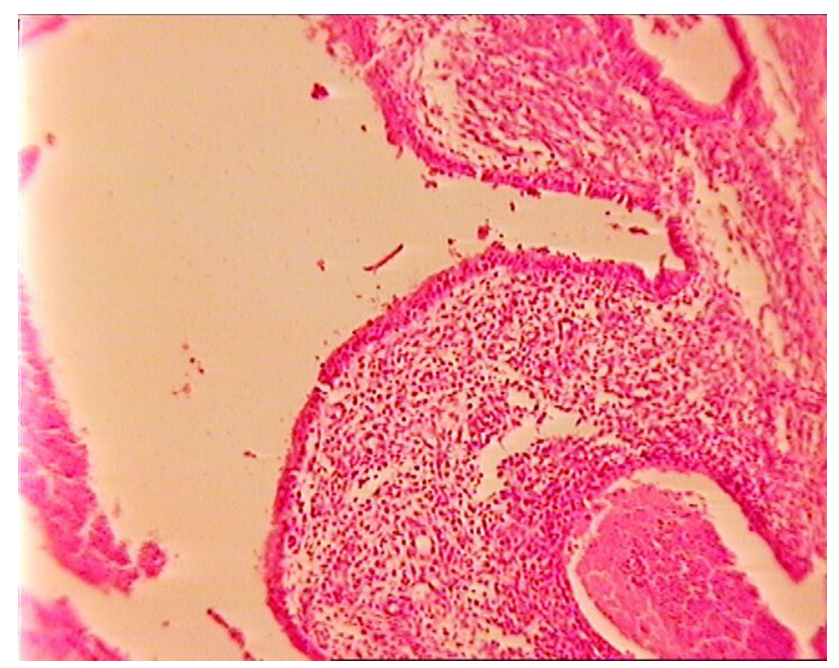

Fig. 2 Section shows an epidermis lined tissue

surgery. Surgical outcome was successful with painless subsequent menstruation and no recurrence till date.

\section{Conclusion}

A comprehensive history and meticulous pelvic examination are essential to the diagnosis of perineal endometriosis. Interval between surgical procedure and development of symptoms is highly variable.

Surgical intervention is the best approach for treatment, and permanent cure is usually achieved after excision of the perineal endometriosis.

\section{Case Discussion}

Scar endometriosis is a rare entity. The incidence has been estimated to be only $0.03-0.15 \%$ of all cases of endometriosis [1]. The incidence of episiotomy scar endometriosis was estimated to be 15 of 2028 consecutive deliveries [2].

Patil et al. [3] studied 17 cases of extrapelvic endometriosis in a time span of 15 years and found a total of three cases of episiotomy scar endometriosis.

Luterek et al. reported a case of a 33-year-old woman with a medical history of recurrent perianal endometriosis. An endometriotic giant mass $(8 \mathrm{~cm}$ in diameter) was widely excised together with the episiotomy scar. They concluded that a wide excision is mandatory as it is the only way to prevent tumour recurrence [4].

Treatment of choice is wide excision of the lesion and medical management, if required. Only medical treatment with the use of progestogen, oral contraceptive pills and danazol is not effective and gives only partial relief in symptoms. Recently, there has been report of use of gonadotropins agonist but only with prompt improvement in symptoms with no change in the lesion size. These patients need to be followed up because of the chances of recurrence, which require re-excision. In case of continual recurrence, possibility of malignancy should be kept in mind [5].

\section{Compliance with Ethical Standards}

Conflict of interest Dr. Shanti Jeyaseelan and Dr. Neha kwatra declare that they have no conflict of interest.

\section{References}

1. Francica G, Giardiello C, Angelone G, et al. Abdominal wall endometriosis near cesarean delivery scars. J Ultrasound Med. 2003;22:1041-7.

2. Paul T, Tedeschi LG. Perineal endometriosisat the site of episiotomy scar. Obstet Gynecol. 1972;40:28-34.

3. Patil BS, Tripathi JB, Patil FB, et al. Extrapelvic endometriosis: a study of 17 cases. J South Asian Fed Obster Gynecol. 2012;4(1): $32-4$.

4. Luterek K, Barcz E, Bablok L, et al. Giant recurrent perineal endometriosis in an episiotomy scar-a case report. Ginekol Pol. 2013;84(8):726-9.

5. Park SW, Hong SM, Wu HG, et al. Clear cell carcinoma arising in a cesarean section scar endometriosis. J Korean Med Sci. 1999;14:217-9. 